06;08

\title{
Синтез, состав, фотолюминесценция, стабильность свойств коллоидных квантовых точек на основе антимонида индия
}

\author{
() Д.В. Крыльский ${ }^{1}$, Н.Д. Жуков 2 \\ ${ }^{1}$ Научно-исследовательский институт прикладной акустики, Дубна, Московская обл., Россия \\ ${ }^{2} \mathrm{OOO} \mathrm{„НПП} \mathrm{Волга“,} \mathrm{Саратов,} \mathrm{Россия}$ \\ E-mail:krdvmail@mail.ru
}

Поступило в Редакцию 29 декабря 2018 г.

В окончательной редакции 13 мая 2019 г.

Принято к публикации 13 мая 2019 г.

Синтезированы и исследованы коллоидные квантовые точки на основе $\mathrm{InSb}$ без оболочки и с оболочками $\operatorname{InP}, \mathrm{CdS}, \operatorname{InP} / \mathrm{CdS}$ и $\operatorname{InP}(\mathrm{Cd}) / \mathrm{CdS}$. Наилучшие результаты по фотолюминесценции и ее стабильности показали квантовые точки с двухслойной оболочкой $\operatorname{InP}(\mathrm{Cd}) / \mathrm{CdS}$. Результаты объяснены в рамках моделей экситонного механизма рекомбинации и квантово-размерного электронного ограничения изоморфной двухслойной оболочкой.

Ключевые слова: коллоидные квантовые точки, антимонид индия, фотолюминесценция, фотостабильность.

DOI: 10.21883/PJTF.2019.16.48147.17665

В настоящее время наиболее изученными являются коллоидные квантовые точки (КТ) на основе широкозонных полупроводников $\mathrm{A}_{2} \mathrm{~B}_{6}$ - халькогенидов кадмия с возможностью их использования в качестве фотолюминофоров. Перспективы расширения применения КТ в электронике связаны прежде всего с продвижением в инфракрасный и терагерцевый спектральные диапазоны, для этого требуются узкозонные и бесщелевые полупроводники [1]. В связи с этим представляют интерес полупроводники $\mathrm{A}_{3} \mathrm{~B}_{5}$, имеющие самый широкий диапазон свойств, наилучшие параметры размерного квантования и возможности большого выбора с учетом разных требований. Публикации по результатам исследований КТ на основе $\mathrm{A}_{3} \mathrm{~B}_{5}$ многочисленны, но в большинстве своем посвящены эпитаксиально-мезоструктурным вариантам. Исследования коллоидных КТ $\mathrm{A}_{3} \mathrm{~B}_{5}$ находятся в начальной стадии [2,3].

Одним из важнейших представителей группы полупроводников $\mathrm{A}_{3} \mathrm{~B}_{5}$ является антимонид индия ( $\mathrm{InSb}$ ), для которого характерна экстремально малая величина эффективной массы электронов проводимости $\left(m \sim 0.014 m_{0}\right.$, где $m_{0}-$ масса „свободного“ электрона) и малая масса дырок $\left(m_{h} \sim 0.25 m_{0}\right)$, что определяет относительно большой радиус экситона Бора $(\sim 60 \mathrm{~nm})[3,4]$. Указанные свойства делают InSb весьма перспективным материалом для изготовления различных приборов [5]. Несмотря на это, существует мало публикаций, посвященных его синтезу. Одной из проблем в данном случае является отсутствие удобных методов синтеза, обусловленное ковалентным характером химической связи в системах $\mathrm{A}_{3} \mathrm{~B}_{5}$, приводящим к медленной кристаллизации, необходимости увеличения температуры и длительности процесса. Другой проблемой является бедный выбор прекурсоров, что в свою очередь ограничивает экспери- ментальные возможности метода [3,5]. Используемые в качестве прекурсоров силиламиды индия [3,6] коммерчески недоступны, крайне чувствительны к воздуху и влаге, требуют достаточно сложного синтеза и очистки.

В работах [4-6] описаны варианты коллоидного синтеза монодисперсных нанокристаллов $\mathrm{InSb}$. В качестве прекурсоров используются хлорид индия $\left(\mathrm{InCl}_{3}\right)$ и трис[бис(триметилсилил)амид] сурьмы $\mathrm{Sb}\left[\mathrm{N}\left(\mathrm{Si}-(\mathrm{Me})_{3}\right)_{2}\right]_{3}$ в олеиламине в присутствии триэтилборгидрида лития $\left(\mathrm{LiEt}_{3} \mathrm{BH}\right)$ в качестве восстанавливающего агента. Предложен метод синтеза наночастиц $\mathrm{InSb}$ с одновременным восстановлением и микроволновым ассистированием („microwave-assisted phase transfer coreduction“, MW-PTCR). Успешно синтезированы сферические наночастицы размером $\sim 5 \mathrm{~nm}$. Синтез проводится на воздухе при нормальном давлении.

В связи с изложенным выше в настоящей работе опробованы модифицированные методы коллоидного синтеза квантовых точек антимонида индия без оболочки (KT InSb) и с разными вариантами оболочек: KT InSb/CdS, InSb/InP, InSb/InP/CdS и InSb/InP(Cd)/CdS.

Коллоидный синтез ядер КT InSb проводился нами в среде безводного олеиламина, в качестве прекурсоров использовались хлорид индия $\left(\mathrm{InCl}_{3}\right)$ и трис[бис(триметилсилил)амид] сурьмы $\mathrm{Sb}\left[\mathrm{N}\left(\mathrm{Si}-(M e)_{3}\right)_{2}\right]_{3}$ согласно методике [4]. Дополнительная модификация методики заключалась в том, что в качестве прекурсора индия использована смесь ацетата и хлорида индия в соотношении $4: 1$. Галогенид в системе необходим для реакции, а добавка ацетата позволила свести к минимуму агрегационные процессы. Прекурсоры выдерживались в течение $20 \mathrm{~min}$ при перемешивании в среде аргона при подбираемых значениях температуры для получения КТ с люминесценцией в требуемом спектральном диапазоне. 
Данные рентгеновских измерений состава (mass \%)

\begin{tabular}{|c|c|c|c|c|c|c|c|c|c|}
\hline \multirow{4}{*}{ Номер образца } & \multirow{4}{*}{ Квантовые точки } & \multicolumn{8}{|c|}{ Элемент } \\
\hline & & In & $\mathrm{Sb}$ & $\mathrm{Cd}$ & $\mathrm{P}$ & $\mathrm{S}$ & $\mathrm{C}$ & $\mathrm{O}$ & \multirow{3}{*}{ Bce } \\
\hline & & \multicolumn{7}{|c|}{ Атомный вес } & \\
\hline & & 114 & 122 & 112 & 31 & 32 & 12 & 16 & \\
\hline 1 & $\mathrm{InSb}$ & 35.09 & 41.89 & - & - & - & - & 23.02 & 100 \\
\hline 2 & $\mathrm{InSb} / \mathrm{InP}(\mathrm{Cd}) / \mathrm{CdS}$ & 5.01 & 2.09 & 49.32 & 4.25 & 17.12 & 20.98 & 1.23 & 100 \\
\hline
\end{tabular}

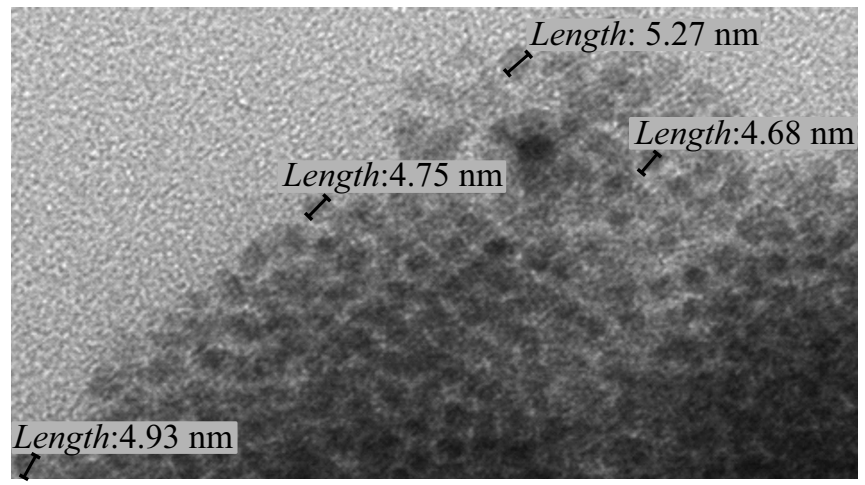

Рис. 1. Результат ПЭМ-исследования КT InSb.

Наращивание оболочки $\mathrm{CdS}$ проводилось с использованием в качестве прекурсоров растворов олеата кадмия $0.2 \mathrm{M}$ и 1-октантиола $0.24 \mathrm{M}$ в октадецене [7]. Для наращивания оболочек были приготовлены объемы прекурсоров в расчете на 6-8 монослоев согласно методу SILAR с учетом разбавления [8].

Наращивание оболочки InP проводилось с использованием трис-(диэтиламин)фосфина по методике [9]. Сделана попытка двухстадийного наращивания оболочек со сложной структурой (InP/CdS), а также одностадийного наращивания оболочек со структурой $\operatorname{InP}(\mathrm{Cd}) / \mathrm{CdS}$.

Все варианты используемых для оболочек материалов изоморфны и имеют в кристаллической структуре значения постоянной решетки, меньшие, чем для антимонида индия, что важно для свойств размерного ограничения в КТ. Кроме того, оболочки выполняют пассивирующие функции, важность которых показана в ряде работ [10].

Синтезированные квантовые точки растворялись, хранились и исследовались в ксилоле с защитой от агрегации и окисления с помощью гексадециламина и триоктилфосфина соответственно. Объемная доля КТ в растворе варьировалась от 10 до 15\%.

Размеры наночастиц определялись методом динамического светорассеяния с помощью прибора Malvern Zetasizer и электронно-микроскопического исследования на просвечивающем микроскопе (ПЭМ) Libra-120. Размеры одиночных и сегрегированных KT InSb в суспензии, определенные с помощью Zetasizer, находились в интервале 4-20 nm. ПЭМ-исследования фрагментарных скоплений одиночных КT InSb позволили выявить их размеры: $4.5-5.5 \mathrm{~nm}$ (рис. 1 ).

Элементный состав слоя наночастиц на подложке контролировался рентгеновским микроанализом на сканирующем электронном микроскопе Mira II LMU, оснащенном системой энергодисперсионных спектрометров INCA Energy 350. Оцениваемая опытным путем точность определения атомного состава материала не хуже $1 \%$. Непосредственно перед измерениями квантовые точки освобождались от лиганда и антиоксиданта на их поверхности, редиспергировались в легколетучий гексан и высаживались островками на кремниевую подложку толстым слоем (не менее $10 \mu \mathrm{m}$ ).

В таблице приведены измеренные по нескольким точкам каждого образца средние значения весовых долей элементов в двух крайних случаях по их количеству в КТ: при минимальном (KT InSb) и максимальном (KT InSb/InP(Cd)/CdS) количестве.

Как видно из таблицы, в варианте КT InSb хорошо проявились индий с сурьмой и кислород. Это может означать, что произошло окисление конгломерированных в наночастицы квантовых точек, несмотря на принятые меры по максимально быстрому процессу подготовки образцов на воздухе перед помещением их в вакуумную камеру электронного микроскопа. Таким образом, отсутствие оболочки для KT InSb недопустимо с точки зрения получения необходимых уровня и стабильности их свойств.

Для варианта $\mathrm{InSb} / \mathrm{InP}(\mathrm{Cd}) / \mathrm{CdS}$ (см. таблицу) хорошо проявились все компоненты состава образцов, практически нет кислорода и заметно наличие углерода. Это можно объяснить тем, что для КТ со сложной относительно толстой оболочкой окисления почти не происходит, что важно для практики. Кроме того, наличие оболочки, видимо, препятствует освобождению от лиганда и антиоксиданта поверхности КТ, о чем свидетельствуют обнаруженные при измерении следы углерода. Кроме того, полученное (см. таблицу) соотношение весовых долей тяжелых элементов ( In, Sb, Cd) может указывать на то, что кадмий находится на поверхности наночастиц $\mathrm{InSb}$, а сам слой, содержащий кадмий (CdS), сравнительно толстый. Можно также утверждать, что оболочка $\mathrm{CdS}$ проявляет защитные стабилизирующие свойства.

Спектры поглощения КТ измерялись на спектрофотометре Varian Cary 100 Bio с шагом $1 \mathrm{~nm}$ в кювете 

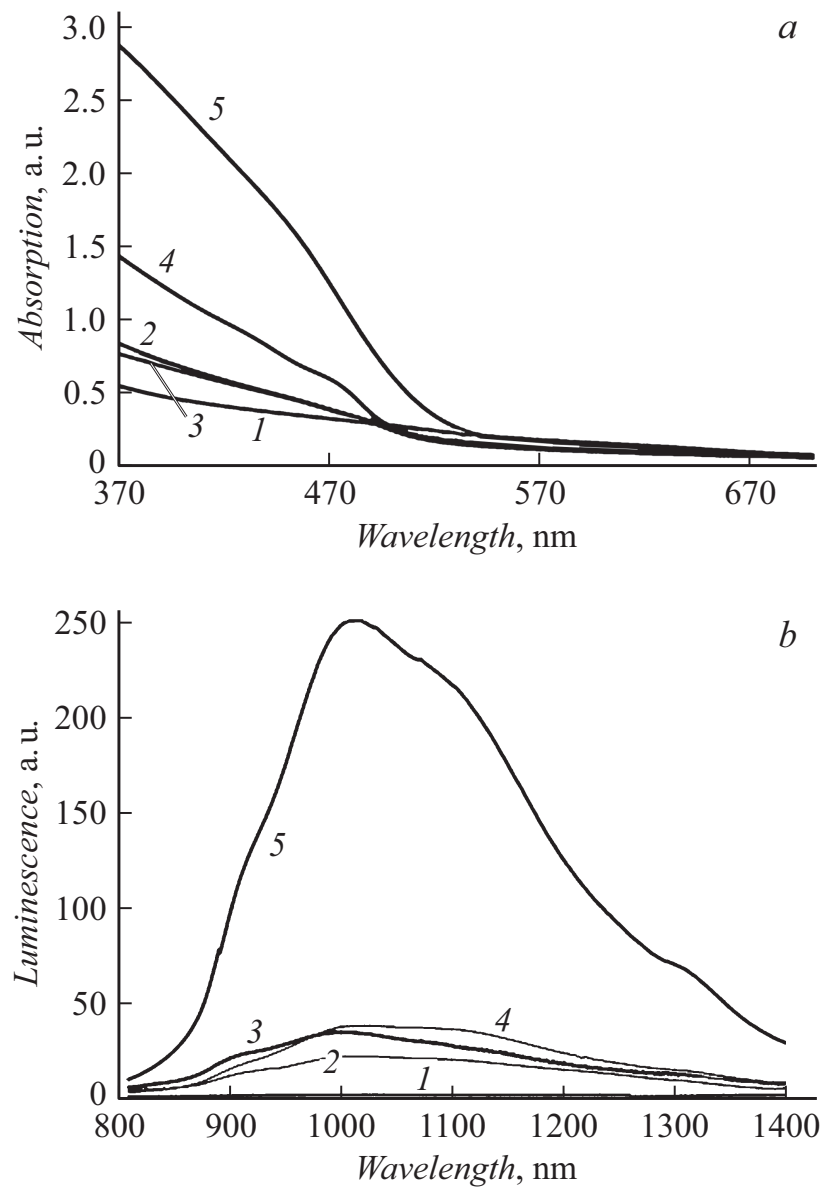

Pис. 2. $a-$ спектры оптического поглощения КT $\mathrm{InSb}$ : 1 - InSb, $2-\mathrm{InSb} / \mathrm{InP}, 3-\mathrm{InSb} / \mathrm{CdS}, 4-\operatorname{InSb} / \mathrm{InP}(\mathrm{Cd}) / \mathrm{CdS}$, 5 - InSb/InP/CdS; $b$ - спектры фотолюминесценции квантовых точек в растворе ксилола: $1-\mathrm{InSb}, 2-\mathrm{InSb} / \mathrm{InP}$, 3 - InSb/CdS, 4 - InSb/InP/CdS, $5-\mathrm{InSb} / \mathrm{InP}(\mathrm{Cd}) / \mathrm{CdS}$. По вертикали - интенсивность излучения, по горизонтали длина волны.

размером $1 \times 1 \mathrm{~cm}$. Спектры фотолюминесценции были получены на спектрофлуориметре HORIBA Fluorolog-3.

На рис. 2, $a$ представлены спектры оптического поглощения KT InSb без оболочки и для трех вариантов толщины оболочки: монослойной, промежуточной, многослойной. Как видно из рисунка, спектры имеют типичный для квантовых точек вид.

Согласно данным [4], интенсивность люминесценции ядер InSb при комнатной температуре очень низкая, квантовый выход не более $1 \%$. Наращивание оболочки $\mathrm{CdS}$ на ядра InSb приводит примерно к 200-кратному возрастанию интенсивности люминесценции. При этом положение максимума около $1500 \mathrm{~nm}$ не изменяется [4]. В настоящей работе получен схожий результат, при этом максимум люминесценции ядер $\mathrm{InSb}$ без оболочки и с оболочкой $\mathrm{CdS}$ лежит в области $1040 \mathrm{~nm}$, наращивание оболочки $\mathrm{CdS}$ на ядра $\mathrm{InSb}$ приводит примерно к 20кратному возрастанию интенсивности люминесценции (рис. 2,b).
На рис. $2, b$ приведены типичные спектры люминесценции для всех вариантов синтезированных КТ. Как видно из рисунка, наращивание дополнительных оболочек на ядро InSb приводит к существенному увеличению квантового выхода и соответственно интенсивности люминесценции КТ. Наибольшая интенсивность люминесценции достигнута для КТ $\operatorname{InSb} / \operatorname{InP}(\mathrm{Cd}) / \mathrm{CdS}$ (она более чем в 100 раз превышает таковую для „чистых“ ядер $\mathrm{InSb})$.

Как известно, наличие в структуре КТ защитной оболочки из более широкозонного по сравнению с ядром полупроводника приводит к стабилизации КТ и повышению квантового выхода [11]. При этом для получения частиц ядро-оболочка с удовлетворительными оптическими свойствами необходимо, чтобы структуры ядра и оболочки были изоморфными, а параметры элементарной ячейки близкими.

Результаты исследований фотостабильности путем облучения КТ ультрафиолетом с длиной волны $365 \mathrm{~nm}$ приведены на рис. 3. Наиболее стойкими к облучению оказались $\mathrm{KT} \operatorname{InSb} / \mathrm{InP}(\mathrm{Cd}) / \mathrm{CdS}$, для которых наблюдалось даже некоторое увеличение интенсивности люминесценции в течение первых $20 \mathrm{~min}$ облучения. Несмотря на усиление агрегационных процессов при облучении ультрафиолетом с длиной волны $365 \mathrm{~nm}$, в течение некоторого времени $(20 \mathrm{~min})$ интенсивность флуоресценции заметно увеличивается, и только при выпадении осадка (после $40 \mathrm{~min}$ ) наблюдается снижение квантового выхода. Одним из возможных объяснений этого может быть возникновение плазменного резонанса на агрегированных частицах [12].

Вероятность излучательной рекомбинации и связанный с ней квантовый выход люминесценции в условиях размерного ограничения движения носителей в квантовой точке определяются вероятностью встречи электрона и дырки и временем жизни их связанного состояния (экситона). Для узкозонных полупроводников с

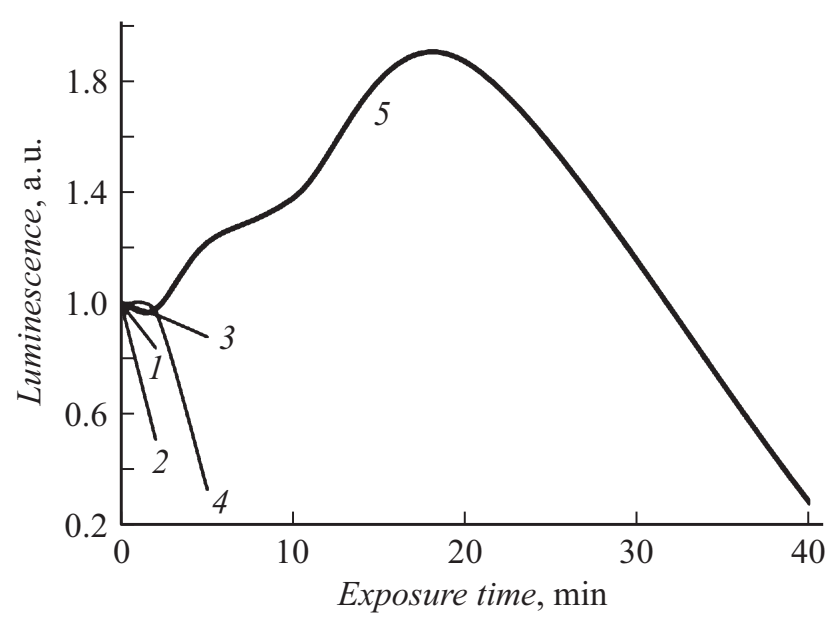

Рис. 3. Фотостабильность синтезированных КТ: $1-\mathrm{InSb}$, $2-\mathrm{InSb} / \mathrm{InP}, 3-\mathrm{InSb} / \mathrm{InP} / \mathrm{CdS}, 4-\mathrm{InSb} / \mathrm{CdS}$, $5-\mathrm{InSb} / \mathrm{InP}(\mathrm{Cd}) / \mathrm{CdS}$. 
суперподвижными носителями образование экситонного состояния маловероятно [13], т. е. фотолюминесценция в $\mathrm{KT} \mathrm{InSb} \mathrm{должна} \mathrm{быть} \mathrm{практически} \mathrm{нулевой,} \mathrm{что} \mathrm{и} \mathrm{наблю-}$ дается экспериментально (рис. 2, b, кривая 1). Сильное ограничение движения носителей (конфайнмент) может резко увеличить вероятность экситонных состояний, чему способствуют экстремально малые размеры КТ и эффективная оболочка. Однако даже в этих случаях эффективность люминесценции весьма низкая (рис. 2, $b$, кривые 2-4). В работе [14] для случаев сильного конфайнмента (размеры KT InSb 5-6 nm) дано объяснение безызлучательного распада экситонов за счет междолинных взаимодействий носителей и существенного влияния стехиометрии КТ.

Таким образом, создание многослойной оболочки с постепенным увеличением ширины запрещенной зоны в слоях приводит к дополнительной стабилизации и повышению квантового выхода КТ. Кроме того, модификация промежуточного слоя InP добавкой Cd приводит к максимальному квантовому выходу в структуре $\mathrm{InSb} / \mathrm{InP}(\mathrm{Cd}) / \mathrm{CdS}$.

\section{Благодарности}

Авторы благодарны С.В. Дежурову и И.Т. Ягудину за оказанную помощь при изготовлении структур и измерениях их свойств.

\section{Финансирование работы}

Исследование выполнено при финансовой поддержке Российского фонда фундаментальных исследований в рамках научных проектов № 18-07-00586-а и 17-07-00139-a.

\section{Конфликт интересов}

Авторы заявляют, что у них нет конфликта интересов.

\section{Список литературы}

[1] Reiss P., Carriere M., Lincheneau C., Vaure L., Tamang S. // Chem. Rev. 2016. V. 116. P. 10731-10819.

[2] Nozik A.J., Beard M.C., Luther M., Law M., Ellingson R.J., Johnson J.C. // Chem. Rev. 2010. V. 110. P. 6873-6890.

[3] Tamang S., Kim K., Choi H., Kim Y., Jeong S. // Dalton Trans. 2015. V. 44. P. $16923-16928$.

[4] Liu W., Chang A.Y., Schaller R.D., Talapin D.V. // J. Am. Chem. Soc. 2012. V. 134. P. 20258-20261.

[5] Yaemsunthorna K., Thongtemb T., Thongtemc S., Randorn C. // Mater. Sci. Semicond. Proc. 2017. V. 68. P. 53-57.

[6] Yarema M., Kovalenko M.V. // Chem. Mater. 2013. V. 25. P. $1788-1792$.

[7] Дежсуров С.В., Трибонов А.Ю., Ловыгин М.В., Рыбакова А.В., Крыльский Д.В. // Рос. нанотехнологии. 2016. Т. 11. № 5-6. C. 54-59.
[8] Wang M., Chen P., Gamelin D.R., Zakeeruddin S.M., Grätzel M., Nazeeruddin Md.K. // Nano Lett. 2009. V. 9. P. 4221-4227.

[9] Shen W., Tang H., Yang X., Cao Z., Cheng T., Wang X., Tand Z., You J., Deng Z. // J. Mater. Chem. C. 2017. V. 5. P. 8243-8249.

[10] Rossinelli A.A., Riedinger A., Marqués-Gallego P., Knüsel P.N., Antolinez F.V., Norris D.J. // Chem. Commun. 2017. V. 53. P. $9938-9941$.

[11] Norris D.J., Efros A.L., Erwin S.C. // Science. 2008. V. 319. P. 1776-1779.

[12] Zhang Z., Wu Y., Dong J., Gao W., Han Q., Zheng H. // J. Phys.: Condens. Matter. 2016. V. 28. P. 364004.

[13] Покутний С.И. // ФТП. 2010. Т. 44. В. 4. С. 507-512.

[14] Sills A., Harrison P., Califano M. // J. Phys. Chem. Lett. 2016. V. 7. P. 31-35. DOI: $10.1021 /$ acs.jpclett.5b02408 